\title{
EL DECRETO DE ALARMA: RANGO JERÁRQUICO Y CONTROL DE CONSTITUCIONALIDAD (UN CAMBIO DE CRITERIO)
}

\author{
JOSÉ MARÍA LAFUENTE BALLE \\ Profesor Titular de Derecho Constitucional \\ Universidad de Girona
}

TRC, n. ${ }^{\circ} 48,2021$, pp. 343-374

ISSN 1139-5583

SUMARIO

\begin{abstract}
I. Planteamiento. II. Los Reales Decretos de declaración del estado de alarma. La inclusión de ultra vires. III. El rango normativo del Decreto de declaración del estado de alarma: origen de la cuestión. IV. El voto particular de los Magistrados D. Luis I. Ortega Álvarez, D. Javier Delgado Barrio y D. Pablo Pérez Tremps. v. La doctrina del Tribunal Supremo. VI. El recurso de inconstitucionalidad 2054/2020. La STC 148/2021 de 14 de julio. Y el recurso de amparo sub iudice. VII. El parámetro de control del decreto de alarma. Enunciado del problema de su rango jerárquico. VIII. Mi cambio de criterio. Justificación. IX. Las tesis del prof. Carlos Garrido López. X. Réplica en favor del diferente rango jerárquico de los reales decretos de declaración del estado de alarma y del de prórroga del estado de alarma.
\end{abstract}

\section{PLANTEAMIENTO}

En sendos artículos de 1989 y $1990^{1}$ sostuve que tanto el decreto gubernamental de declaración del estado de alarma como la autorización parlamentaria para su prórroga tenían rango de norma reglamentaria, susceptible del control de legalidad por parte de la jurisdicción ordinaria. Este artículo en el 2021 ha de

1 Lafuente Balle, J. M.a: «Los estados de alarma, excepción y sitio (I)», Revista de Derecho Político, n. ${ }^{\circ} 30,1989$. Y «Los estados de alarma, excepción y sitio (II)», Revista de Derecho Político, n. ${ }^{\circ}$ 31, 1990, pp. 34 y 42 . 
servir para explicar las razones de mi parcial cambio de criterio. La juventud entonces de la Constitución (y la mía), los años transcurridos y la aplicación práctica en el 2020 del art. 116.2 CE con motivo de la pandemia de la COVID 19 son sin duda las causas de este cambio de opinión.

El art. 116 de la Constitución es un ejemplo paradigmático de ambigüedad constitucional. Regula el estado de alarma, el de excepción y el de sitio con expresa omisión de cuáles son los «efectos» de cada uno de ellos. Por sus definiciones sabemos que son instrumentos de limitación, suspensión y restricción de derechos. Y también que los requisitos de su procedimiento de aprobación han de estar en consonancia con la gravedad de las medidas que aprueben.

Así pues, si la aprobación del estado de sitio exige la mayoría absoluta del Congreso de los Diputados, sus efectos habrán de ser necesariamente más graves que los del estado de excepción cuya declaración exige tan solo la previa autorización del Congreso de los Diputados. Y, a su vez, los efectos del estado de excepción serán más graves que los del estado de alarma que es declarado por el Gobierno sin ninguna intervención del Congreso de los Diputados salvo para su prórroga.

Y hete aquí la disfunción: la declaración del estado de alarma está regulada en el art. 116.2 CE. Este precepto establece que será declarado por el Gobierno mediante decreto. Pues bien, el Tribunal Constitucional ha resuelto atribuir rango legal a este decreto gubernamental a pesar de que el Parlamento tiene una nula intervención en su aprobación.

Es sabido que el orden jerárquico del ordenamiento jurídico (Constitución-ley-reglamento) responde a la lógica de la teoría de la representación en la que se fundamenta la Democracia misma ${ }^{2}$. El rango jerárquico de una norma está en función del grado de representatividad del órgano que la ha aprobado: La Constitución es aprobada directamente por el Pueblo y por tanto tiene representación de primer grado; las leyes la tienen de segundo grado porque las aprueba el Parlamento elegido por el Pueblo; y los reglamentos de tercer grado porque los dicta el Gobierno elegido por el Parlamento. Conforme a esta lógica de la representatividad, las leyes no pueden contradecir a la Constitución porque el Parlamento no puede contradecir al Pueblo que lo ha elegido. Y los reglamentos administrativos no pueden contradecir a las leyes porque el Gobierno no puede contradecir al Parlamento que lo ha investido 3 .

Pues bien, según la doctrina del Tribunal Constitucional, el decreto del estado de alarma es la única norma del sistema de fuentes estatales que tiene rango legal sin ninguna intervención del órgano legislativo. En todas las demás o interviene el Congreso y el Senado (la reforma constitucional, los estatutos de

2 Kelsen, H.: Reine Rechtslabre Deuticke, Viena 1934. Traducción al español, Teoría pura del Derecho. Eudeba. Buenos Aires, 1976.

3 Lafuente Balle, J. M. a: Introducción al Derecho Constitucional: La Constitución en acción. Civitas Thomson Reuters, Madrid 2012, pp. 31 a 34. 
autonomía y las demás leyes orgánicas, leyes ordinarias, los tratados internacionales, los decretos legislativos) o solo el Congreso (el Reglamento del Congreso, los decretos leyes, los decretos de excepción y de sitio) o solo el Senado (el Reglamento del Senado, el acuerdo del art. 155 de la Constitución de la coerción esta$\left.\mathrm{tal}^{4}\right)$. La intervención del Parlamento es precisamente lo que dota de rango legal a una norma.

¿Tiene pues el decreto de declaración del estado de alarma rango legal? De la respuesta depende que su control corresponda al Tribunal Constitucional o a la Jurisdicción contencioso administrativa. Si tiene rango legal, su control es de constitucionalidad y compete al Tribunal Constitucional ex art. 161.1.a). Pero si no fuese así y su rango no fuese legal sino reglamentario, su control correspondería a los Juzgados y Tribunales del orden contencioso administrativo ex art. 1 LJCA 29/1998 y conforme al art. 97 de la Constitución.

La LOTC forma parte del criterio de constitucionalidad para declarar la conformidad constitucional de una ley (art. 28). Su art. 27.2 enumera las normas con rango y fuerza del ley susceptibles de control de constitucionalidad. El apartado b) de este artículo se refiere a «los actos del Estado con fuerza de ley». Este junk drawer no parece argumento suficiente para incluir actos del poder ejecutivo sin ninguna intervención del legislativo; ¿o sí?

El Tribunal Constitucional entró en esta cuestión para resolver en favor del rango legal de la autorización parlamentaria de prórroga del Decreto de alarma. Así sucedió con motivo del Auto 7/2012 de 13 de enero a propósito del recurso de amparo instado por los controladores aéreos de AENA frente al acuerdo del Pleno del Congreso de los Diputados de 16 de diciembre de 2010, de autorización de la prórroga del estado de alarma declarado por Real Decreto 1673/2010, de 4 de diciembre en cuyo art. 3 se disponía que todos los controladores de tránsito aéreo al servicio de AENA pasaban a tener la consideración de personal militar, sometidos a las autoridades militares y a las leyes penales y disciplinarias militares, de conformidad con el art. 8 de la Ley Orgánica 13/1985, de 9 de diciembre, penal militar:

«En definitiva, se trata de decisiones o actos parlamentarios que, aunque no dictados en el ejercicio de la potestad legislativa de la Cámara ni revestidos, en consecuencia, de la forma de ley, configuran el régimen jurídico del estado de emergencia en cada caso declarado, repercutiendo en el régimen de aplicabilidad de determinadas normas jurídicas, incluidas las provistas de rango de ley, normas a las que, como ya hemos señalado, pueden, con taxativas condiciones, suspender o desplazar durante el período de vigencia del estado de emergencia de que se trate. Dada su cualidad de decisiones o actos parlamentarios con valor de ley, el cauce para

4 Lafuente Balle, J. M.: El art. 155 de la Constitución española: examen doctrinal y comparado, en Revista de Derecho Político, n. ${ }^{\circ}$ 102, 2018, pp. 79-122; y El art. 155 de la Constitución española (el acuerdo del Senado), en Revista de Derecho Político, n. ${ }^{\circ} 103,2018$, pp. 77-116. 
residenciarlos ante la jurisdicción constitucional no es, en lo que aquí importa, el recurso de amparo del art. 42 LOTC, para el que basta la legitimación individual del art. 162.1 b) CE, sino el de inconstitucionalidad, con la legitimación que le es propia, o, en su caso, la cuestión de inconstitucionalidad. Se advierte así, en definitiva, la lógica institucional que subyace a la salvedad presente en el inciso inicial del art. 42 LOTC.».

Y la reciente STC 148/2021 de 14 de julio expresamente remite el problema al precedente del ATC 7/2012 de 1.3 de enero

Así pues, el criterio del Tribunal Constitucional para decidir sobre el carácter legislativo de la autorización parlamentaria de la prórroga de un Decreto de alarma se ha extrapolado a la declaración misma del estado de alarma. Este es el criterio del Tribunal Constitucional y, al ser reiterativo, dificulta su objeción. Sin embargo, lo que en este trabajo se pretende analizar no afecta a la prórroga del estado de alarma sino a la declaración gubernamental del estado de alarma. No cuestiono que la prórroga sea un acto parlamentario y, por ende, con fuerza de ley. Sin embargo, la declaración del estado de alarma es un acto estrictamente gubernamental falto de toda intervención parlamentaria y, por consiguiente, de una más que dudosa naturaleza legislativa.

\section{LOS REALES DECRETOS DE DECLARACIÓN DEL ESTADO DE ALARMA. LA INCLUSIÓN DE ULTRA VIRES}

El problema planteado se plasma tanto en el Real Decreto 463/2020 de 14 de marzo como en el Real Decreto 926/2020 de 25 de octubre ${ }^{5}$. Ambos respondieron a la pandemia del COVID 19. Conforme al art. 116.2 de la Constitución fueron acordados por el Gobierno sin ninguna intervención del Congreso de los Diputados al que se dio cuenta. Ahora bien, uno y otro real decreto suscitan una problemática sustancialmente diferente.

En el primer estado de alarma, el Real Decreto 463/2020 de 14 marzo se declaró por plazo de 15 días (art. 3). Todas sus hasta seis prórrogas sucesivas (25 de marzo, 9 de abril, 22 de abril, 6 de mayo, 20 de mayo y 3 de junio de 2020) precisaron del debate y la autorización del Congreso de los Diputados (art. 6.2 Ley orgánica 4/1981) en otras tantas sesiones plenarias con debate y votación de la propuesta del Gobierno, así como las de los demás Grupos Parlamentarios (art. $162 \mathrm{RCD})$.

En la segunda declaración del estado de alarma acordada en el Real Decreto 926/2020, el Gobierno modificó la estrategia parlamentaria; y la cambió

5 Ridao i Martín, J.: Derecho de crisis y Estado autonómico. Del estado de alarma a la cogobernanza en la gestión de la COVID-19, Marcial Pons, Madrid, 2021. Analiza los distintos reales decretos y decretos promulgados durante el estado de alarma. 
precisamente para evitar esos debates parlamentarios. Por imperativo constitucional, el Real Decreto 926/2020 acordó una duración de 15 días hasta el 9 de noviembre. Ahora bien, como ni el texto del art. 116.2 de la Constitución ni el texto del art. 6.2 Ley orgánica 4/1981 establecen ningún límite de duración para la prórroga, el Gobierno sometió a la aprobación del Congreso de los Diputados una prórroga de seis meses hasta el 9 de mayo de 2021 que dio lugar al Real Decreto 956/2020.

El 27 de octubre (es decir, dos días después del Real Decreto 926/2020 de declaración del segundo estado de alarma) el Consejo de Ministros adoptó el Decreto de prórroga. Dos días después, el 29 de octubre, el Pleno del Congreso de los Diputados autorizó el Decreto de prórroga. En suma, en apenas 5 días, el acuerdo de declaración fue prorrogado por seis meses. O lo que es lo mismo, el inicial acuerdo de declaración del estado de alarma duró apenas cuatro días, del 25 al 29 de octubre de 2020.

Y hete aquí que cabe formular otra importante cuestión: ¿Convalida la autorización parlamentaria a prorrogar la declaración del estado de alarma los ultra vires del Real Decreto? ¿Opera la autorización del Congreso de los Diputados al modo del art. 86.3 de la Constitución para los Decretos Leyes?

En el primer estado de alarma, el Real Decreto 463/2020 de 14 de marzo incluyó medidas de alcance constitucional, especialmente la limitación de la libertad de circulación (art. 7); la autorización de requisas de bienes necesarios e imposición de prestaciones personales (art. 8); la suspensión de actividades educativas, comerciales, culturales, recreativas, hosteleras, religiosas (arts. 9 a 11). Estas medidas permanecieron sin intervención o autorización parlamentaria doce días hasta la prórroga del 25 de marzo.

De igual modo, en el segundo estado de alarma, el Real Decreto 926/2020 de 25 de octubre impuso medidas de la misma trascendencia constitucional y decretó la limitación de circulación en horario nocturno (art. 5) y perimetral entre las autonomías (art. 6); la limitación del derecho de manifestación y de reunión incluso en lugares de culto (arts. 7 y 8). El Congreso de los Diputados no intervino en la adopción de estas medidas sino hasta que cuatro días después autorizó la prórroga del estado de alarma.

Atendido el silencio del art. 116.2 de la Constitución, para conocer el alcance del estado de alarma procede acudir al art. 11 de la Ley orgánica 4/1981 que es el que establece las medidas del estado de alarma: limitación de la circulación o permanencia; imponer requisas temporales; intervenir establecimientos industriales; racionar el consumo de productos básicos; impartir órdenes para asegurar el abastecimiento. De estas cinco medidas posibles, los dos Reales Decretos 463/2020 y 926/2020 han regulado la primera: Limitar la circulación o permanencia de personas o vebiculos en horas y lugares determinados, o condicionarlos al cumplimiento de ciertos requisitos.

$\mathrm{Y}$ es en este punto cuando procede reformular la pregunta: ¿Puede el Gobierno sin autorización parlamentaria adoptar medidas que no se atienen a los 
arts. 116.2 de la Constitución y 11 de la Ley orgánica 4/1981? ¿Y si media la autorización parlamentaria? ¿Son los ultra vires del Real Decreto controlables por la jurisdicción ordinaria?

La STC 148/2021 de 14 de julio (Ponente Mgtdo. Pedro González-Trevijano Sánchez) ha dado respuesta a estos interrogantes. Por una mayoría de 6 votos frente a 5, el Pleno del Tribunal estimó parcialmente el recurso de los diputados de Vox frente al Real Decreto 463/2020 de 14 de marzo y declaró inconstitucional su arts. 7 (Limitación de la libertad de circulación de las personas): apartados 1 (salvo para para proveerse de productos de primera necesidad, asistencia sanitaria, desplazamientos al lugar de trabajo y domicilio habitual, asistencia a dependientes, desplazamientos a entidades financieras y de seguros, fuerza mayor); 3 (circulación de vehículos para las actividades enumeradas y repostaje); 5 (facultad del Ministerio del Interior de cerrar la circulación en carreteras).

El fundamento esencial de la Sentencia es la diferenciación entre los conceptos de limitación y suspensión. El estado de alarma permite tan solo la limitación de derechos. Solo los estados de excepción y de sitio regulan la suspensión de los derechos y libertades constitucionales.

Sostiene que las medidas previstas en el Real Decreto 463/2020 de 14 de marzo, art. 7, apartados 1, 3, 5 vulneran los derechos recogidos en la Constitución, arts. 19 (derecho a la libre circulación por todo el territorio nacional) y 21 (derecho de reunión y manifestación); y en la Ley orgánica 4/1981.

Argumenta que es inherente a la libertad de circulación su irrestricto despliegue y práctica en las vías o espacios de uso público para aquellos fines que solo el titular del derecho puede determinar.

La inconstitucionalidad se fundamenta en que esas drásticas medidas del Real Decreto 463/2020, art. 7 han supuesto la suspensión del derecho a circular libremente, esto es la cancelación temporal del ejercicio de este derecho; la amputación material del derecho a mantener reuniones privadas y domésticas; y la vulneración del derecho a elegir libremente la propia residencia, trasladarla o modificarla.

El Tribunal no se constriñe a resolver la inadecuación del estado de alarma para las medidas decretadas por el Gobierno, sino que además añade que estas suspensiones solo están previstas en los casos de declaración de los estados de excepción y de sitio ex art. 55.1 CE.

En fin y en relación a los procedimientos ordinarios conclusos con Sentencia firme, resuelve que solo cabe la revisión de los procedimientos penales y contencioso-administrativos que hubiesen impuesto penas o sanciones (art. 40.1 L.O.T.C) ${ }^{6}$.

La Sentencia da respuesta a las preguntas formuladas, a saber:

— La posterior autorización del Congreso de los Diputados no convalida los ultra vires del Real Decreto de declaración del estado de alarma dictado

6 Ramón Ribas, E.: Desobediencia, estado de alarma y COVID 19, Tirant lo Blanch, Valencia 2021. 
por el Gobierno. El Magistrado Xiol Rius firma un voto particular y discrepa particularmente de esta aseveración cuando escribe: Aunque se aceptara que el Consejo de ministros cuando aprobó el Real Decreto 463/2020 incurrió en una infracción de la Constitución al haber suspendido derechos fundamentales sin la previa autorización del Congreso, este vicio habria sido subsanado por esta Cámara al hacer suyas en su integridad las medidas acordadas por el Gobierno. El órgano competente para otorgar la autorización (el Congreso de los Diputados) al prorrogar las medidas adoptadas por el Consejo de Ministros, las confirmó, lo que supone asumir como propio lo acordado por el Gobierno. Para que un órgano pueda subsanar los actos dictados por otro es necesario que el ordenamiento le baya otorgado potestades para reformar la decisión de aquel y en este caso es claro que la Constitución atribuye al Congreso potestades para reformar las medidas adoptadas por el Gobierno. Por ello puede mantenerse que la prórroga integra de tales medidas corrigió el defecto inicial en el que incurrió el Gobierno al adoptar medidas suspensivas de derechos fundamentales (según mantiene la mayoría) sin la preceptiva autorización del Congreso y convalidó los preceptos que establecieron estas medidas (los apartados 1, 3 y 5 del art. 7 del Real Decreto)

- Si el Gobierno incluyó en el Real Decreto normas que exceden los límites del estado de alarma, la autorización parlamentaria de su prórroga no implica ninguna convalidación de las vulneraciones a la Constitución.

- La suspensión de derechos no puede acordarse mediante la declaración del estado de alarma, sino solo a través de los estados de excepción o de sitio.

- El parámetro de constitucionalidad de un Real Decreto ex art. 116 CE no es solo la Constitución sino también la Ley orgánica 4/1981.

A mi entender y conforme al art. 38.1 L.O.T.C sobre el efecto extensivo de las sentencias del Tribunal Constitucional con efectos generales para todos los Poderes Públicos, la STC 148/2021 de 14 de julio tiene efectos sobre el segundo estado de alarma objeto del Real Decreto 926/2020 de 25 de octubre, particularmente su art. 7.3 que faculta al Gobierno o, por delegación, a la autoridad autonómica, a «prohibir» reuniones en tránsito público cuando no quede garantizada la distancia personal.

La Sentencia 148/2021 de 14 de julio mereció hasta cinco votos particulares. El Presidente Juan José González Rivas considera que las limitaciones del art. 7 están amparadas en La Ley orgánica 4/1981, arts. 11 (limitación de la circulación 0 permanencia de personas o vehiculos en horas y lugares determinados o condicionarlas al cumplimiento de ciertos requisitos) y 12 (facultad de la Autoridad competente para adoptar por sí, según los casos, además de las medidas previstas en los artículos anteriores, las establecidas en las normas para luchar contra enfermedades infecciosas...) y no implican ninguna suspensión de derechos.

Coinciden los Magistrados Andrés Ollero Tassara y M. ${ }^{a}$ Luisa Balaguer Callejón, y sostienen que el dilema planteado entre el estado de alarma y el estado de excepción se remite a los supuestos de hecho de cada uno. El de excepción está 
previsto para graves alteraciones del orden público. El de alarma para casos de catástrofes naturales y pandemias. Al entender del Magtdo. Ollero Tassara, el estado de alarma solo deviene inconstitucional cuando a posteriori se detecta que la limitación de derechos ha sido desproporcionada para la solución del supuesto de hecho que dio origen a la declaración. Para aplicar la Ley orgánica 4/1981 y optar por el estado de alarma o el de excepción debe atenderse a la situación de pandemia y no a los efectos que provoca el art. 7 del Real Decreto 463/2020 de 14 de marzo sobre la libertad de circulación. Ambos coinciden en que la Ley no contempla que sea la mayor o menor gravedad de la afectación de los servicios públicos esenciales la causa para sostener que se debió sustituir el estado de alarma por el estado de excepción. La Mgtda. Balaguer Callejón, por su parte, invoca la aplicación de un canon de constitucionalidad basado en el principio de proporcionalidad de las medidas adoptadas para preservar el derecho a la salud, la vida y la integridad física. Argumenta la incorrección lógica de la Sentencia puesto que son las causas habilitantes del estado de alarma y del de excepción las que condicionan la opción por uno u otro tipo de estado excepcional.

El Magistrado Cándido Conde-Pumpido Tourón advierte que la Sentencia abre un grave problema político y sanitario porque priva al Estado del instrumento que la ley establece a través del estado de alarma para combatir las crisis sanitarias. En su opinión, sería radicalmente contrario a la Constitución declarar el estado de excepción para hacer frente a una pandemia. Conforme a la Constitución y a la ley orgánica 4/1981, una pandemia no produce ninguna alteración del orden público y, en consecuencia, no procede declarar el estado de excepción con la consiguiente suspensión de derechos fundamentales.

Y en fin, el Magistrado Juan Antonio Xiol Rius emite un larguísimo voto particular. Parte de la premisa de que cada uno de los estados de emergencia ex art. 116 CE y Ley orgánica 4/1981 responden a causas perfectamente distintas y, por eso, para que proceda la declaración de uno u otro ha de concurrir el presupuesto habilitante. Sobre esta premisa, subraya que el presupuesto es la pandemia y que el estado previsto al efecto es el de alarma y no el de excepción que está previsto para el presupuesto de una grave alteración del orden público que remite a una crisis de la seguridad ciudadana y la convivencia pacífica de la sociedad. La adopción de un u otro estado depende de la causa y no de la gravedad del presupuesto. Las medidas adoptadas en el art. 7 del Real Decreto 463/2020 de 14 de marzo no implican suspensiones sino limitaciones proporcionales y temporales de derechos constitucionales que tienen por objetivo solventar la situación de emergencia sanitaria con el objetivo de salvaguardar bienes o valores constitucionales. Responde negativamente a la pregunta ¿La declaración del estado de excepción conlleva más garantías para los ciudadanos que la declaración del estado de alarma? porque sostiene que el control parlamentario en el estado de excepción no garantiza que las medidas que se establezcan sean más generosas con la libertad.

Es este último argumento el que me parece más polémico. El Magtdo. Xiol Rius lo argumenta del siguiente modo: 
«A) ¿La declaración del estado de excepción conlleva más garantías para los ciudadanos que la declaración del estado de alarma? (...) Es cierto que en el estado de excepción el control parlamentario existe desde el primer momento, pues para poder ser acordado requiere la previa autorización del Congreso de los Diputados. En cambio, el estado de alarma puede ser declarado por el Gobierno y solo es preciso que dé cuenta a esta Cámara (la autorización del Congreso únicamente es necesaria si se quiere mantener por más de quince días). Ahora bien, aunque la declaración del estado de excepción precise la previa autorización del Congreso, esta exigencia no garantiza que las medidas que se establezcan sean más generosas con la libertad, pues, precisamente, la declaración de estado de excepción requiere la previa autorización del Congreso porque a su amparo se pueden imponer medidas que conllevan la privación temporal de la eficacia de normas constitucionales que garantizan derechos y libertades fundamentales. Esta medida va a ser siempre más restrictiva de la libertad que las limitaciones de derechos fundamentales que puedan establecerse en virtud del estado de alarma, pues estas limitaciones, por muy intensas que sean, no privan de efectos temporalmente a la norma constitucional que lo garantiza.»

A mi entender, cuando de garantías democráticas se trata, el tertium comparationis no es entre el estado de alarma y el de excepción. También en el estado de alarma procede primar la intervención y el control del Parlamento. En la segunda declaración del estado de alarma acordada en el Real Decreto 926/2020, el Gobierno sometió a la aprobación del Congreso de los Diputados una prórroga de seis meses hasta el 9 de mayo de 2021 que dio lugar al Real Decreto 956/2020. Este cambio de estrategia en relación a la primera declaración de la alarma respondió al objetivo de evitar el debate parlamentario cada quince días como sucedió en la primera declaración del estado de alarma. Coincido en que semejante estrategia viene amparada por la letra de la norma constitucional. De facto, ni el texto del art. 116.2 de la Constitución ni el texto del art. 6.2 Ley orgánica 4/1981 establecen ningún límite de duración para la prórroga. Ello no obstante, la estrategia del Gobierno no fue la más sensible a las reglas del parlamentarismo.

Desde esta perspectiva, claramente que la intervención del Parlamento supone siempre un plus garantista. El motivo nos devuelve al principio de este artículo: el principio de representatividad. Mientras que la representatividad del Gobierno es de segundo grado, la representatividad del Parlamento es de primer grado y, en consecuencia, la intervención y el control del Parlamento suponen una mayor garantía democrática.

\section{EL RANGO NORMATIVO DEL DECRETO DE DECLARACIÓN DEL ESTADO DE ALARMA: ORIGEN DE LA CUESTIÓN}

El problema sobre el rango normativo de los decretos del estado de alarma ex art. 116.2 de la Constitución afecta a su inicial declaración por el Gobierno porque para el primer plazo de 15 días no precisa de autorización parlamentaria. 
Desde la declaración de la primera alarma en el Decreto 463/2020 de 14 de marzo hasta su prórroga parlamentaria, transcurrieron nueve días. Del mismo modo, en la segunda alarma, entre la declaración por el Gobierno del Decreto 926/2020 de 25 de octubre y su prórroga parlamentaria, los días fueron cuatro.

El conflicto es de jerarquía normativa. ¿Cómo un decreto del Gobierno, carente de cualquier intervención parlamentaria, podría primar por encima de leyes orgánicas, inclusive de estatutos de autonomía?

Las respuestas posibles son dos.

La primera sería que no obstante ser un decreto gubernamental sin intervención parlamentaria, el decreto de declaración del estado de alarma forma parte de la «legalidad excepcional»y, como tal, tiene rango de ley; y, por ende, solo puede ser controlado vía recurso de inconstitucionalidad.

Los controladores aéreos declarados en huelga en el 2010 instaron un recurso de amparo no solo frente al Decreto 1673/2010 de 4 de diciembre (para la normalización del servicio público del transporte aéreo) sino también frente al Decreto de prórroga 1717/2010 de 17 de diciembre autorizado por el Congreso de los Diputados. Dos son las resoluciones del Tribunal Constitucional y presentan algunas diferencias. El ATC 7/2012 de 13 de enero sostiene que el decreto de declaración del estado de alarma sería una norma sin valor de ley, mientras que el decreto de prórroga autorizado por el Congreso tendría rango de ley: «... se trata de decisiones o actos parlamentarios que, aunque no dictados en el ejercicio de la potestad legislativa de la Cámara ni revestidos, en consecuencia, de la forma de ley, configuran el régimen jurídico del estado de emergencia en cada caso declarado, repercutiendo en el régimen de aplicabilidad de determinadas normas jurídicas, incluidas las provistas de rango de ley...».

La STC 83/2016 de 28 de abril corrige esta interpretación y atribuye valor y rango de ley a ambos decretos: «...ha de resaltarse, además, la peculiaridad de que el decreto de prórroga constituye una formalización ad extra ...). Y resuelve el rango legal tanto del Decreto del Gobierno como de su prórroga (La decisión gubernamental viene así a integrar en cada caso, sumándose a la Constitución y a la Ley Orgánica 4/1981, el sistema de fuentes del derecho de excepción...). Para el Tribunal «Si la Constitución y el ordenamiento habilitan a determinados actos, decisiones o resoluciones parlamentarias para modificar de tal modo la aplicación de las leyes, no es de dudar que tales actos, decisiones o resoluciones ostenten ese genérico rango o valor de ley».

En el caso de la huelga de los controladores aéreos en el 2010, el Tribunal Constitucional resuelve la irrecurribilidad del decreto de alarma por vía de amparo. En sus resoluciones afirma que la autorización del Congreso a la prórroga (arts 116. 2 CE; 6 LO 4/181; 162, 163 RCD) vino a dar al decreto naturaleza y carácter parlamentario con rango y fuerza de ley y, por ende, su exclusión del ámbito de la jurisdicción contencioso administrativa y del recurso de amparo ex art. 42 LOTC. Sostiene el carácter político y discrecional de la decisión del Gobierno (ex art. $97 \mathrm{CE}$ ). Y utiliza el argumento recurrente de que el estado de alarma (con el de excepción y el de sitio) conforma un sistema de fuentes del derecho de excepción en 
defensa del orden constitucional que implica la suspensión temporal de la legalidad ordinaria, la limitación de derechos constitucionales ( $\mathrm{A}$ diferencia de los estados de excepción y de sitio, la declaración del estado de alarma no permite la suspensión de ningún derecho fundamental...») y la habilitación de disposiciones y actos administrativos durante su vigencia. Y concluye que el fundamento de la declaración de cualquiera de estos estados es siempre la imposibilidad en que se encuentran las autoridades competentes para mantener mediante los poderes ordinarios la normalidad ante la emergencia de determinadas circunstancias extraordinarias.

\section{EL VOTO PARTICULAR DE LOS MAGISTRADOS D. LUIS I. ORTEGA ÁLVAREZ, D. JAVIER DELGADO BARRIO Y D. PABLO PÉREZ TREMPS}

Hasta tres magistrados del Tribunal formularon un voto particular al Auto $7 / 2012$. Se da la particular circunstancia de que ninguno de los tres formaba ya parte del Pleno del Tribunal que dictó la Sentencia 83/2016 de 28 de abril. Luis I. Ortega Álvarez falleció el 15 de abril de 2015. Javier Delgado Barrio y Pablo Pérez Tremps fueron cesados, respectivamente, el 20 de julio de 2012 y el 12 de junio de 2013. De hecho de los Magistrados que dictaron el ATC 7/2012 solo dos permanecían en el Tribunal al dictar la STC 83/2016: d. Francisco Pérez de los Cobos Orihuel y dña. Adela Asúa Batarrita.

En su recurso de amparo, los abogados de los controladores civiles negaron que el decreto tenga rango o fuerza de ley porque carecería de naturaleza parlamentaria y no consta enumerado en el art. 27 LOTC. Comparan el decreto de alarma y sus efectos ad extra con los acta interna corporis y sus efectos ad intra. E insisten en que la militarización de los controladores aéreos (atribución al Jefe del Estado Mayor del Ejército del Aire de facultades absolutas laborales sobre los controladores aéreos) fue un ultra vires por exceder las disposiciones previstas en la Ley orgánica 4/1981, arts. 4 (presupuestos de la alarma), 9 (subordinación de todos los funcionarios a la Autoridad competente) y 12 (facultades de la Autoridad competente); y también por contravenir la Ley 39/2007 de la carrera militar así como la Ley orgánica 4/1987 de competencia y organización de la jurisdicción militar; y en fin por limitar y vulnerar derechos constitucionales (arts. 20, 21, 22, 23, 24, 28, 29).

Pues bien, haciéndose eco de estos argumentos, los Magistrados discrepantes sostienen que ni el decreto de declaración de la alarma ni la autorización parlamentaria de su prórroga tengan rango y valor de ley. Su argumentación es breve pero contundente y alegan que el art. 116 de la Constitución no les reconoce semejante calificación: «...la Constitución deja claro el rango normativo de los instrumentos por los que se declara el estado de alarma y de excepción, sin que esta claridad pueda ser interpretada por este Tribunal en la forma en que lo ha hecho la mayoría». 


\section{LA DOCTRINA DEL TRIBUNAL SUPREMO}

La doctrina del Tribunal Supremo al respecto de los decretos de declaración del estado de alarma ha venido confirmando los precedentes a propósito del Real Decreto 1673/2010 de 4 de diciembre dictado con motivo de la huelga de los controladores aéreos. Entonces, la Sala Tercera del Tribunal Supremo dictó hasta siete Autos: AATS 857/2011, de 10 de febrero; 2985/2011, de 9 de marzo; $3816 / 2011$, de 5 de abril; 5696/2011 y 5698/2011, de 30 de mayo; 6821/2011, de 8 de junio; y 6197/2012, de 1 de junio.

Ya en el primero, el ATS 857/2011, invocó el art. 5.2 LJCA para inadmitir el recurso contencioso-administrativo por falta de jurisdicción: «La razón de que así deba ser es que la impugnación va dirigida contra un acto cuyo contenido ha sido asumido en su integridad por el Congreso de los Diputados desde el momento en que autorizó la prórroga del Estado de Alarma en los mismos términos en que inicialmente fue declarado...». Esta tesis fue confirmada en el ATS 2985/2011: «Es claro, pues, que no se está ya ante una actuación del Gobierno sino ante una resolución de la Cámara ejercitando una de las funciones que la Constitución le atribuye, como también lo es que esta resolución, como fue razonado en el auto que se recurre y ahora debe repetirse, está fuera del genérico ámbito delimitado para el control jurisdiccional en el artículo 106.1 de la Constitución...».

El Tribunal Supremo ha mantenido esta doctrina en la posterior Jurisprudencia dictada con motivo de la declaración del estado de alarma a consecuencia de la pandemia del COVID 19: Procede la inadmisión de recursos contencioso administrativos contra los Reales Decretos por lo que se declara el estado de alarma o su prórroga. Ahora bien, se admite a trámite el incidente como cautelar de un recurso por el procedimiento especial de protección de derechos fundamentales de la persona (circulación, vida, integridad física y psíquica, honor y propia imagen, libertad individual, reunión y manifestación, información, igualdad, asociación).

Los argumentos para la inadmisión son reiterativos (AATS de 4 de mayo, Ponente Mgtdo. Jorge Rodríguez-Zapata Pérez; de 6 de mayo, Ponente Mgtda. M. ${ }^{a}$ del Pilar Teso Gamella; de 7 de octubre de 2020, Ponente Mgtdo. Rafael Toledano Cantero; 14 de octubre de 2020, Ponente Mgtdo. Pablo M. ${ }^{a}$ Lucas Murillo de la Cueva; 5 de noviembre de 2020, Ponente Mgtda. M. ${ }^{a}$ del Pilar Teso Gamella; 1569/2020 de 20 de noviembre, Ponente Mgtda. Celsa Picó Lorenzo; 25/2021 de 26 de enero, Ponente Mgtda. Celsa Picó Lorenzo; 87/2020 de 8 de marzo, Ponente Mgtdo. Pablo M. ${ }^{a}$ Lucas Murillo de la Cueva; 86/2021 de 9 de marzo, Ponente Mgtdo. Luis M. ${ }^{a}$ Díez-Picazo Giménez; 93/2021 de 18 de marzo, Ponente Mgtdo. Pablo M. ${ }^{a}$ Lucas Murillo de la Cueva; de 24 de junio de 2021, Ponente Mgtdo. Antonio Jesús Fonseca-Herrero Raimundo).

- Los precedentes de los AATS 553/2011 de 10 de febrero, 180/2011 de 5 de abril, 152/2011 de 30 de mayo, 153/2011 de 30 de mayo. 
- Los decretos impugnados no atienden a la potestad reglamentaria del Gobierno; son disposiciones con rango y valor de ley que responden a un acto de la competencia constitucional exclusiva del Gobierno; y su prórroga por el Congreso de los Diputados a la relación de fiducia entre el Gobierno y las Cortes Generales.

- La declaración del estado de alarma y sus prórrogas conforman un bloque inescindible, en el que tiene una decisiva intervención el Congreso de los Diputados, toda vez que solo puede prorrogarse con autorización expresa del Congreso de los Diputados, ante el que rinde cuentas el Gobierno.

- La declaración del estado de alarma puede llegar a desplazar la aplicación de normas con rango de ley al objeto de restablecer la normalidad.

- La legalidad aplicable durante la vigencia del estado de alarma produce, con mayor o menor intensidad, un cambio en el tradicional sistema de fuentes del Derecho, que es lo que el Tribunal Constitucional denomina «sistema de fuentes del Derecho de excepción».

- Carácter informativo de las recomendaciones de la O.M.S., el Consejo Superior de Investigaciones Científicas, e incluso el Alto Consejo de la Salud Pública de Francia el 20 de agosto de 2020.

- Ausencia de fumus bonus iuris en las solicitudes de suspensión cautelar de los Decretos autonómicos establecidos en aplicación de los Reales Decretos.

- La recurribilidad en vía contencioso-administrativa y de amparo constitucional de los actos o disposiciones generales dictadas en aplicación de los Reales Decretos ex art. 8.2 Ley orgánica 4/1981 de 1 de junio. Si como consecuencia o con ocasión de dichas impugnaciones resultase la existencia de contradicción de las disposiciones normativas contenidas en la declaración de estado de alarma o en sus prórrogas con la Constitución, esta Sala o el órgano jurisdiccional competente en cada caso, promovería cuestión de inconstitucionalidad.

La STS 1595/2020 de 25 de noviembre (Ponente Mgtdo, Rafael Toledano Cantero) acuerda desestimar un recurso contencioso administrativo instado por la Federación Española de Pesca y Casting contra ciertos artículos de la Orden de 9 de mayo de 2020 que excluyen la caza y la pesca deportivas de las medidas de flexibilización en aplicación de la fase 1 del plan para la transición hacia una nueva normalidad.

Y la STS 324/2021 de 9 de marzo (Ponente Mgtdo. Pablo M. ${ }^{a}$ Lucas Murillo de la Cueva) desestima un recurso contencioso administrativo instado contra la Orden de 30 de mayo de 2020 y su art. 7.2 que restringe el derecho de circulación y de reunión a 20 personas con motivo de las medidas de flexibilización en aplicación de la fase 3 del plan para la transición hacia una nueva normalidad. La Sentencia entiende que la Oren no incurre en arbitrariedad y tampoco cabe imputarle la vulneración del derecho fundamental a la reunión: «En consecuencia, no tiene sentido decir que se ha desconocido el sistema de fuentes e infringido el principio de jerarquía normativa ni vulnerado los artículos 53,1 y 81 de la Constitución. En primer lugar, porque la reserva de la ley orgánica es para el desarrollo de los derechos fundamentales y porque la ley ordinaria puede sentar limitaciones a los mismos. En segundo lugar, 
porque la Orden no suspende ningún derecho. En tercer lugar, porque, otra vez hay que acudir a la sentencia del Tribunal Constitucional n. ${ }^{\circ} 83 / 2016 \ldots »$.

Cuestión diferente es la de la admisibilidad de recursos contencioso-administrativos frente a los decretos autonómicos dictados con posterioridad al estado de alarma. La STS 788/2021 de 3 de junio (Ponente Mgtdo. Pablo M. ${ }^{a}$ Lucas Murillo de la Cueva) resuelve sobre el Acuerdo de 17 de mayo de 2021 dictado por el Consejo de Gobierno de la Comunidad Autónoma de las Islas Baleares y falló a favor de la posibilidad de restringir derechos fundamentales sin la cobertura del estado de alarma ${ }^{7}$ :

«Comenzando por la primera parte de la cuestión, de nuestra sentencia n. ${ }^{\circ} 719 / 2021$ ya se desprende que la restricción de derechos fundamentales en el marco de la lucha contra la pandemia del Covid-19 no exige siempre y necesariamente la cobertura del estado de alarma. Entonces se dijo que, al menos en ciertos supuestos, la legislación sanitaria proporciona fundamento normativo suficiente (...). Y, desde luego, esa opción de las instituciones políticas del Estado no puede reputarse jurídicamente vinculante para los tribunales a la hora de dilucidar cuál es el fundamento normativo constitucionalmente requerido para las restricciones de derechos fundamentales (...). El medio normal para aprobar normas que impliquen la restricción o limitación de un derecho fundamental se encuentra, como es sabido, en los arts. 53 y 81 del texto constitucional: dicho medio es la previsión por ley que, en todo caso, debe respetar el contenido esencial del derecho fundamental restringido y, por ello mismo, superar el juicio de proporcionalidad; y es la ley orgánica cuando la restricción prevista suponga desarrollo de alguno de los derechos proclamados en la Sección 1. a del Capítulo II del Título I».

En este mismo sentido se pronuncian, entre otras, las SSTS 792/2021 de 3 de junio (Ponente Mgtdo. Pablo M. ${ }^{a}$ Lucas Murillo de la Cueva) frente a un recurso de la Junta de Andalucía; 719/2021 de 24 de mayo (Ponente Mgtdo. Pablo M. ${ }^{a}$ Lucas Murillo de la Cueva); 875/2021 de 17 de junio (Ponente Mgtdo. José Luis Requero Ibáñez) en la que se analiza la Jurisprudencia de la Sala sobre la autorización de medidas urgentes y necesarias para la salud pública que limiten o restrinjan derechos fundamentales.

\section{EL RECURSO DE INCONSTITUCIONALIDAD 2054/2020. LA STC 148/2021 DE 14 DE JULIO. Y EL RECURSO DE AMPARO SUB IUDICE}

Publicado los Decretos 926/2020 de 25 de octubre y 956/2020 de 3 de noviembre, respectivamente, de declaración del estado de alarma y su prórroga,

7 Lafuente Balle, J. M.a.: «Las decisiones judiciales de los tribunales sobre las normas autonómicas post alarma», Diario de Mallorca, edición del 10 de mayo de 2021. 
el Grupo Parlamentario de Vox presentó un recurso de inconstitucionalidad. Entre otros varios argumentos, en el Fundamento de Derecho Primero, los recurrentes suscitaron el problema del rango jerárquico normativo del Decreto. Sus argumentos principales son los siguientes:

- Apartado 32: Invocan los arts. 9.3 y 53.1 CE. La jurisprudencia del TEDH exige que las limitaciones y restricciones de derechos constitucionales se impongan en una norma de rango legal que reúna los requisitos de calidad, entendida como accesibilidad, precisión y previsibilidad en su aplicación.

- Apartado 43: Aducen la STC 124/2018 de 14 de noviembre, sobre la centralidad del Parlamento en su relación con el Ejecutivo y el carácter esencial de los controles parlamentarios como núcleo de una Constitución democrática.

- Apartado 47: Transcriben la STC 199/2016 de 28 de noviembre, en relación al carácter irrenunciable e indelegable de las funciones del Congreso porque afectan al núcleo esencial del ius in officium de los parlamentarios ex art. 23 CE.

La STC 148/2021 de 14 de julio zanjó la reflexión en apenas un párrafo en el que se limita a reiterar la doctrina del ATC 7/2012 de 13 de enero:

«b) Coinciden las partes en que los reales decretos del Gobierno por los que se declara o se prorroga el estado de alarma constituyen, a efectos de su impugnación por este cauce, actos con rango o valor de ley; apreciación que este Tribunal comparte, con arreglo a su propia doctrina.

Así, a partir de lo ya fundamentado en el ATC 7/2012, de 13 de enero (RTC 2012, 7 AUTO) (FFJJ 3 y 4), la STC 83/2016, de 28 de abril (RTC 2016, 83) (FJ 10), dejó sentado, por lo que aquí interesa que:

(i) "la decisión gubernamental por la que se declara el estado de alarma [...] viene [...] a integral en cada caso, sumándose a la Constitución (RCL 1978, 2836) y a la Ley Orgánica 4/1981 (RCL 1981, 1291), el sistema de fuentes del derecho de excepción», de modo que la «legalidad excepcional que contiene la declaración gubernamental desplaza durante el estado de alarma la legalidad ordinaria en vigor, en la medida en que viene a excepcionar, modificar o condicionar durante ese periodo la aplicabilidad de determinadas normas, entre las que pueden resultar afectadas leyes, normas o disposiciones con rango de ley, cuya aplicación puede suspender o desplazar".

(ii) En correspondencia con ello, "aunque formalizada mediante decreto del Consejo de Ministros, la decisión de declarar el estado de alarma, dado su contenido normativo y efectos jurídicos, debe entenderse que queda configurada en nuestro ordenamiento como una decisión o disposición con rango o valor de ley" y "revestida de un valor normativo equiparable, por su contenido y efectos, al de las leyes y normas asimilables cuya aplicación puede excepcionar, suspender o modificar durante el estado de alarma". 
(iii) "por idénticas razones, no puede ser distinta la conclusión en relación con el rango o valor del decreto por el que se prorroga el estado de alarma”; hipótesis en la que, además, el decreto gubernamental constituye una formalización ad extra de la previa autorización del Congreso de los Diputados. Acto parlamentario al que corresponde fijar el alcance, condiciones y términos de la prórroga y que a su vez ostenta ( ATC 7/2012, de 13 de enero (RTC 2012, 7 AUTO), FJ 4) la condición de decisión con rango o valor de ley. De suerte que los reales decretos de declaración y prórroga de un estado de alarma "sólo cabe impugnarlos, de acuerdo con el modelo de jurisdicción de nuestro ordenamiento jurídico, ante este Tribunal Constitucional a través de los procesos constitucionales [...] que tienen por objeto el control de constitucionalidad de las leyes, disposiciones y actos con fuerza o valor de ley"».

Ciertamente llama la atención la brevedad y la contundencia de la argumentación, tanto más atendido el voto particular de hasta tres magistrados al ATC 7/2012 de 13 de enero. Ahora bien, no es menos cierto que en la demanda del recurso de inconstitucionalidad, el abogado firmante tampoco dio a este problema mayor relevancia, tal vez porque en su estrategia procesal, prefirió centrarse en otros argumentos más sensibles que finalmente serían parcialmente estimados.

En un recurso de amparo paralelo instado por la Diputada del Grupo Parlamentario de Vox Dña Macarena Olona Choclán se reitera la cuestión del rango jerárquico de la norma (Motivos del Amparo Primero-B). Sus argumentos se fundamentan precisamente en el voto particular al ATC 7/2012 de 13 de enero, a saber:

— Siendo la Constitución la Norma Normarum le es dable atribuir a concretas normas el privilegio formal y material de la fuerza de ley cuando, aun sin proceder formalmente del Parlamento, ostentan ese carácter (arts. 82.1, $86 \mathrm{CE})$.

- El art. 116 de la a Constitución no atribuye fuerza de ley a ninguna de las normas, disposiciones o actos que se dicten en esos estados de emergencia constitucional.

- La Constitución ha decidido otorgar a la ciudadanía, titular de la soberanía, una capacidad reactiva frente a las disposiciones y actos de emergencia que no tendría de ostentar rango legal.

- El rango de ley que el Auto 7/2012 y la STC 83/2016 atribuyen a las disposiciones y actos en estados de emergencia ha privado a la ciudadanía de una defensa real y efectiva frente a las intromisiones que en sus derechos puedan producirse.

- De aceptarse la fuerza de ley de la autorización de prórroga, el derecho de participación política de la diputada recurrente resultaría desprotegido ex art. 23 CE.

Aun excediendo del objeto estricto de este trabajo, el recurso n. ${ }^{\circ}$ 2054/2020 planteó un intenso debate en la comunidad académica de los constitucionalistas. 
La Constitución establece en su art. 116 la legitimación para la declaración y la atribuye al Gobierno en el estado de alarma y al Congreso en los de excepción y de sitio. Además en su artículo 55.1, la Constitución constriñe la «suspensión» de derechos a los estados de excepción y de sitio pero en ningún caso al estado de alarma. En fin, no es la Constitución sino la Ley orgánica 4/1981 la que enumera los supuestos de hecho para cada uno de los tres estados de alarma, de excepción y de sitio.

La doctrina constitucionalista viene debatiendo sobre si las medidas adoptadas por el Gobierno para la pandemia y, particularmente, el toque de queda, implicaban solo una «limitación» de derechos o más bien una «suspensión» de derechos. En el primer caso, el estado de alarma era el instrumento legal oportuno; pero en el segundo supuesto, habría sido preciso decretar el estado de excepción.

Con dúplicas y réplicas, tres constitucionalistas mantuvieron en el diario madrileño El País un debate que ha trascendido por su interés. En primer lugar fue el prof. López Basaguren ${ }^{8}$ quien utilizó el histórico debate entre los lacedenios (partidarios de primar la necesidad sobre la ley), y Octavio y Catón, (favorables a ley antes que a la necesidad) para concluir su tesis en favor de la constitucionalidad del decreto de alarma.

Le respondió el prof. Aragón Reyes? ${ }^{9}$. Advierte que la enumeración de los supuestos de hecho en que procede la declaración de uno u otro estado no está prevista en la Constitución, sino en la Ley orgánica 4/1981. Bajo esta premisa, cuando se trate de limitar derechos, el instrumento adecuado es el estado de alarma. Pero cuando se pretenda suspender derechos, cualquiera que sea el supuesto de hecho, procederá declarar el estado de excepción. De este modo concluye que es la ley la que se debe interpretar conforme a la Constitución y no viceversa.

La réplica corrió a cargo del prof. García Roca ${ }^{10}$. Parte del principio de permanencia de la legislación impugnada en caso de duda. Y en este caso, la duda es tanto mayor cuanto que las normas que regulan la excepcionalidad no pueden prever todos los supuestos. Continúa invocando el principio de proporcionalidad de las medidas adoptada para combatir una pandemia de tan notable gravedad. Sostiene que las medidas adoptadas no suspenden sino que «restringen» derechos conforme, además, al asentimiento del Congreso con motivo de las prórrogas autorizadas.

En fin la dúplica fue publicada por el prof. Aragón Reyes ${ }^{11}$ en una carta al diario. Insiste en que la alarma no permite la suspensión de derechos y que, en consecuencia, el decreto impugnado es inconstitucional; y que no es la Constitución la que ha de interpretarse de conformidad a la ley orgánica, sino esta de

8 López Basaguren, A: «Estado de alarma: ¿Octavio y Catón en el Constitucional?», El País, edición del 29 de junio de 2021.

9 Aragón Reyes, M.: «¿Alarma o excepción?», El País, edición del 6 de julio de 2021.

10 García Roca, J.: «La constitucionalidad de la alarma», El País, edición del 12 de julio de 2021.

11 Aragón Reyes, M.: «Estado de alarma y Constitución», El País, edición del 14 de julio de 2021. 
conformidad con la Constitución; y que el principio de proporcionalidad sirve para limitar derechos pero no para suspenderlos.

La polémica trascendió a la publicación de la propia STC n. ${ }^{\circ}$ 148/2021 de 14 de julio y continuó en otros tres artículos, cronológicamente, de Tomás de la Quadra Salcedo ${ }^{12}$, Javier García Roca ${ }^{13}$ y Manuel Aragón Reyes ${ }^{14}$.

\section{EL PARÁMETRO DE CONTROL DEL DECRETO DE ALARMA. ENUNCIADO DEL PROBLEMA DE SU RANGO JERÁRQUICO}

La doctrina del Tribunal Constitucional y del Tribunal Supremo plantea el problema del control de constitucionalidad del decreto de alarma. Veamos: si como dicen estos dos tribunales, el decreto solo es susceptible de control a través del recurso de inconstitucionalidad, procederá determinar cuál es el parámetro de su constitucionalidad ex art. 28 L.O.T.C. La Doctrina ha abordado esta cuestión y particularmente el prof. Castilla Abella ${ }^{15}$.

Claramente el parámetro vendría dado por la propia Constitución. Pero, en mi opinión, también por la Ley orgánica 4/1981 porque se trataría de una norma con rango de ley que regula materias reservadas a la ley orgánica ex arts. 81.1 y 116.1 C.E., además de la L.OT.C. y el Reglamento del Congreso de los Diputados.

Así pues, el Tribunal Constitucional tendría que estimar un recurso (o una cuestión) de inconstitucionalidad instado frente a un decreto de alarma que vulnerase el art. 116.1 C. E o los arts. 1 a 12 de la Ley orgánica 4/1981.

El prof. Castilla Abella discrepa de este criterio porque el decreto de alarma tendría rango de ley y, por ende, el mismo que la ley orgánica: «Pero, con el principio de jerarquía normativa en mano, resultaría ilógico sostener que el ajuste del decreto de alarma a la LO 4/1981 condiciona su validez y tampoco puede resolverse la cuestión acudiendo a la distinción entre ley ordinara y ley orgánica. Cuando en un conflicto entre ambos tipos de leyes debe acudirse a la constitución para saber a cuál corresponde regular esa materia (reservas de ley orgánica en la Constitución). Pero en este caso no es posible utilizar ese criterio por la razón de que aquí no hay reserva alguna en favor de la ley orgánica frente al decreto de alarma, o viceversa».

Resulta claro que la cuestión del parámetro de control de la constitucionalidad del decreto de alarma presupone determinar cuál es su rango jerárquico. Para

12 De la Quadra Salcedo, T.: «Rompiendo el consenso constitucional», El País, edición del 22 de julio de 2021.

13 García Roca, J.: «Una controvertida decisión», El País, edición del 27 de julio de 2021.

14 Aragón Reyes, M.: «El Tribunal Constitucional cumplió», El País, edición del 4 de agosto de 2021.

15 Castillo Abellá, J.: «¿Ley o reglamento? El decreto de emergencia como una nueva categoría en nuestro ordenamiento», Instituto de Derecho Local, 13 de mayo de 2020, pp. 1-7. 
quienes han defendido su rango reglamentario, el control del decreto de declaración del estado de alarma será de legalidad y corresponderá a la jurisdicción ordinaria. Por el contrario si el decreto de declaración del estado de alarma tiene rango de ley, su control será de constitucionalidad y competerá al Tribunal Constitucional. Pero aun en esta segunda alternativa, suscita si el parámetro de constitucionalidad es solo la Constitución, tal y como sostiene el prof. Castillo Abello, o también la Ley orgánica 4/1981.

En este sentido, continúa con su argumentación y concluye que el caso del decreto de alarma «recuerda, en cierto modo, al de la legislación delegada (...) lo cierto es que en ambas la actuación del Gobierno tiene rango de ley en virtud de una habilitación específica y limitada. En el caso de la legislación delegada, esa habilitación se articula a través de una ley de delegación y tiene su fundamento en el art. 82 CE. Para el decreto de alarma, la habilitación podría hallarse en el art. 116 CE y estaría desarrollada en la LO 4/1981». Conforme a este criterio, tanto el decreto de alarma como el decreto de alarma prorrogado tendrían rango de ley con la virtualidad de desplazar la aplicación de otras normas con idéntico rango de ley.

Advierte este autor de su discrepancia con el ATS 99/2020 de 4 de mayo cuando contempla la competencia del Tribunal Supremo ex art. 2 L.J.C.A. para conocer de la impugnación de los decretos de alarma no prorrogados o de los que no se hubiera dado cuenta al Congreso de los Diputados. Su opinión se fundamenta en que no advierte diferencia entre un decreto de alarma prorrogado y otro que no lo ha sido; y porque durante el plazo de los 15 días de la declaración gubernamental, el decreto habría desplazado la aplicación de otras normas con rango de ley.

\section{POSICIONES DOCTRINALES}

En los primeros estudios doctrinales tras la aprobación de la Constitución, varias voces cualificadas ${ }^{16}$ sostuvieron que las declaraciones gubernamentales del art. 116 de la Constitución son actos políticos exentos de cualquier control jurisdiccional, inclusive del Tribunal Constitucional. El debate sobre los actos políticos del Gobierno y su exclusión de control jurisdiccional ha perdido vigencia a partir de la nueva redacción del art. 2.a de la LJCA. Mientras que la redacción del

16 Embid Irujo, A.: «La justiciabilidad de los actos del Gobierno. (De los actos políticos a la responsabilidad de los poderes públicos)», Documentación Administrativa, n. ${ }^{2}$ 22, 1989, pp. 20-66; FERNÁNDEZ SEgado, F.: «La Ley Orgánica de los estados de alarma, excepción y sitio», Revista de Derecho Político, n. ${ }^{\circ} 11$, 1981, pp. 98 y 99; Serrano Alberca, J. M.: «Comentario al artículo 116» en Garrido Falla, F. (dir.): Comentarios a la Constitución, Civitas, Madrid, 2001 (ediciones anteriores de 1980 y 1985) pp. 1787, 1788; MAteu-Ros Cerezo, R.: «Estados de alarma, excepción y sitio» en AA.VV.: «Gobierno y Administración en la Constitución», Instituto de Estudios Fiscales, Madrid, 1988, vol. I, p. 195. 
art. 2.b en la LJCA de 1956 especificaba que los actos políticos del Gobierno estaban excluidos del orden jurisdiccional contencioso-administrativo, la actual redacción de 1998 establece que cualquiera que fuese su naturaleza, los actos del Gobierno central y de los Gobiernos autonómicos están sujetos al conocimiento de la jurisdicción contencioso-administrativa. Claro está que esta jurisdicción está expresamente limitada cuando se trata de las decisiones gubernamentales con fuerza de ley cuyo control de constitucionalidad compete al Tribunal Constitucional.

Esto supuesto, las posiciones actuales en la doctrina, enfrentan dos criterios, a saber:

A) Un primer sector sostiene que el decreto gubernamental de declaración del estado de alarma y el posterior con autorización parlamentaria para su prórroga tienen el mismo estatuto jurídico. Aún en esta corriente doctrinal los autores se dividen según aboguen por el control de jurisdicción ordinaria 0 el de la jurisdicción constitucional. Todo depende del rango jerárquico del decreto gubernamental de declaración y del rango jerárquico del decreto posterior con autorización parlamentaria para su prórroga.

Si ese estatuto fuese el propio de una norma con rango reglamentario, el control sería de legalidad y correspondería a la jurisdicción contencioso-administrativa ex art. 106.1 CE.

Si este estatuto fuese el propio de una disposición normativa con rango de ley, el control sería de constitucionalidad y deberá corresponder al Tribunal Constitucional ex art. 161.1.a CE.

a) La posición doctrinal partidaria de que los decretos de declaración de alarma y de su prórroga tienen ambos rango reglamentario y están sujetos al control de legalidad de la jurisdicción ordinaria ex art. 106.1 CE.

Esta es la posición que yo sostuve en sendos artículos de 1989 y $1990^{17}$. Anteriormente la había defendido el prof. Cruz Villalón ${ }^{18}$. En cuanto que normas de rango reglamentario, sus ultra vires serían susceptibles de control de legalidad por la jurisdicción contencioso-administrativa. Este control afectaría tanto a defectos de forma como a excesos materiales, es decir tanto a un decreto de alarma que no respete el procedimiento previsto en la Ley orgánica o en el Reglamento parlamentario; pero también a un decreto que no se atenga a los supuestos de hecho del art. 4 de la Ley orgánica o que conlleve una restricción de derechos no contemplada en el art. 11 de la Ley orgánica.

17 Lafuente Balle, J. M. a: «Los estados de alarma, excepción y sitio (I)», Revista de Derecho Político, n. ${ }^{\circ}$ 30, UNED, Madrid 1989. Y «Los estados de alarma, excepción y sitio (II)», Revista de Derecho Político, n. ${ }^{\circ}$ 31, UNED, Madrid 1990, pp. 34 y 42.

18 Cruz Villalón, P.: «El nuevo derecho de excepción», Revista Española de Derecho Constitucional, n. ${ }^{\circ}$ 2, 1981, pp. 115 y 116. V. también Estados excepcionales y suspensión de garantías, Ed. Tecnos, Madrid 1984. 
La postura ha ido sumando partidarios. La prof. Requejo Rodríguez ${ }^{19}$ sostiene que la autorización parlamentaria de la prórroga no puede suponer una elevación del rango reglamentario del decreto. Y el prof. Villar $C$ respo ${ }^{20}$ se refiere a que pese a la provisionalidad de estos decretos y su naturaleza reglamentaria sui generis, el control de legalidad corresponde a la jurisdicción contencioso-administrativa.

Más recientemente el prof. Fernández de Casadevante Mayordomo ${ }^{21}$ parece adscribirse a esta opción cuando, muy crítico con el Gobierno, escribe: «No es solo que el Gobierno central haya suspendido derechos fundamentales a través de un estado de alarma que no está habilitado para ello. Siendo eso, ya de por sí, suficientemente grave, se ha convertido en norma habitual una práctica que es radicalmente contraria a nuestro ordenamiento jurídico: la regulación de derechos fundamentales a través de simples normas reglamentarias, suspensión general de los mismos incluida»

Esta tesis no obstaría a que el Tribunal Constitucional conociese de un recurso de amparo por vulneración de derechos fundamentales ex art. 43 LOTC; o de un conflicto de competencias entre el Gobierno y el Congreso de los Diputados ex art. 59.1.c LOTC o entre el Estado y una Comunidad Autónoma ex art. 59.1.a LOTC

b) La posición doctrinal partidaria de que los decretos de declaración de alarma y de su prórroga tienen ambos rango legal y están sujetos al control de constitucionalidad del Tribunal Constitucional ex art. 161.1.a CE.

El art. 5.1 de la Ley 50/1997 del Gobierno enumera las funciones del Consejo de Ministros y distingue como diferentes la aprobación de reglamentos ejecutivos (apartado h) de la declaración del estado de alarma (apartado f). Son varios los autores que defienden el rango legal tanto del decreto de declaración de la alarma como del decreto de prórroga. Los profs. Aparicio Pérez ${ }^{22}$, Porres Azkona ${ }^{23}$ y García Cuadrado ${ }^{24}$ argumentan en favor de esta tesis porque sostienen que son

19 Requejo Rodríguez, P.: «Teoría vs práctica del estado de alarma en España» en AA. VV.: Constitución y democracia: ayer y hoy: Libro homenaje a Antonio Torres del Moral, vol II, Universitas, Madrid 2012, pp. 1512 a 1513.

20 Villar Crespo, G.: «Comentario a la STC 83/2016: con motivo de la naturaleza de los decretos del Gobierno que declaran el estado de alarma», Revista General de Derecho Administrativo, n. 48 Iustel, Madrid 2018 , pp. 25 a 27.

21 Fernández de Casadevante Mayordomo, P.: «Desafíos constitucionales ante el coronavirus» en Cobo del Rosal, G. (dir.) y Navalpotro Sánchez-Peinado J. M. ${ }^{a}$ : Derechos fundamentales en estado de alarma: una aproximación multidisciplinar, Dykinson, Madrid 2020, p. 163. Fernández DE CASAdEvante Mayordomo, P.: «El Derecho de emergencia constitucional en España: hacia una nueva taxonomía», Revista de Derecho Político, n. ${ }^{\circ} 107,2020$, pp. 112 a 145.

22 Aparicio PÉrez, M.Á.: «¿Hacia una nueva figura de actos políticos del Gobierno?» en VV. AA.: El Gobierno en la Constitución y en los Estatutos de Autonomía, Diputación de Barcelona, 1985, p. 193

23 Porres Azkona, J.: «La decisión sobre los poderes excepcionales», Revista Vasca de Administración Pública, n. ${ }^{\circ} 6,1983$, pp. 47 a 48 .

24 García Cundrado, J. A.: «Aproximación a una teoría de los "actos constitucionales" ", Revista de Derecho Político, n. ${ }^{\circ}$ 46, 1999 , pp. 44 a 50. 
actos de aplicación inmediata de la Constitución que no tienen su apoyo en la Ley orgánica sino en el mismo art. 116 de la Constitución. Esta circunstancia fundamenta la suspensión temporal de ciertas garantías constitucionales como complemento necesario para la plena efectividad de los arts. 55.1 y 116.

Más recientemente, el prof. Solozábal Echavarría ${ }^{25}$ se adscribe a esta opinión. Tilda la calificación del tipo de norma como un prurito taxonómico discutible. Se remite al ATC 7/2012 de 13 de enero y a la STC 83/2016 de 28 de septiembre para concluir que el decreto de declaración del estado de alarma debe entenderse que queda configurado como una decisión o disposición con rango o valor de ley que desplaza la legalidad ordinaria en la medida en que viene a excepcionar, modificar o condicionar pro tempore la aplicabilidad de normas del ordenamiento jurídico. Integra junto a la Constitución y la Ley orgánica 4/1981 el sistema de fuentes del Derecho de excepción. Del mismo modo, para este autor, tanto a la decisión gubernamental de la prórroga como a la decisión de la autorización parlamentaria de la prórroga les corresponde la condición de decisión con rango o valor de ley. En consecuencia sostiene que el control jurisdiccional compete exclusivamente al Tribunal Constitucional operando según criterios estrictamente técnicos; si bien los actos y disposiciones dictados como consecuencia de los Reales decretos pueden ser recurridos por las personas afectadas vía recurso de amparo previo agotamiento del procedimiento ordinario previo ex art. 55.2 L.O.T.C. También el prof. Álvarez-Ossorio Micheo se adscribe a esta corriente de opinión pero no oculta cierto pesar porque añade que «deja inerme al ciudadano frente al acto de declaración del estado de alarma...» ${ }^{26}$.

Alineándose en esta tesis, destacadamente, el prof. Garrido López ${ }^{27}$ mantiene que esos decretos no son ni actos administrativos, ni actos de Gobierno, ni propiamente normas porque no establecen un mandato general que modifique el ordenamiento jurídico. Antes al contrario, son unos actos infraordenados a la

25 Solozábal Echavarría, J.J.: «Algunas consideraciones constitucionales sobre el estado de alarma». En Biglino Campos, P.; y Durán Alba, J.F. (dirs.): Los efectos horizontales de la Covid-19: estudios sobre la primera oleada. Fundación Manuel Giménez Abad, Universidad de Valladolid, Zaragoza 2021, pp. 28, 30, 31; Téllez Dávila, C.: «Naturaleza jurídica y parámetro de control de los decretos de declaración y prórroga del estado de alarma para la gestión de la crisis sanitaria ocasionada por el COVID-19», Trabajo de final de grado. Facultat de Dret. Universitat de Girona. Mayo 2021. Álvarez VÉlez, M. ${ }^{a}$ I.: «Sistema de fuentes del Derecho y estado de alarma: la STC 83/2016 de 28 de abril», Asamblea. Revista parlamentaria de la Asamblea de Madrid, n. ${ }^{\circ}$ 34, 2016, pp. 325 a 340. CANOSA Usera, R.: «El marco internacional y supranacional de la reacción estatal europea ante la emergencia sanitaria». En Arnaldo Alcubilla, E. y Canosa Usera, R. (dirs.): El Derecho Constitucional ante el COVID-19. Las diferentes respuestas en el ámbito comparado. Ed. Wolters Kluwer, Madrid 2021.

26 Álvarez-Ossorio Micheo, F.: «Los estados de alarma, excepción y sitio». En Cerdeira Bravo de Mansiles, G. (dtor.) y García Mayo, M. (coord.): Coronavirus y Derecho en estado de alarma, Reus, Madrid, 2020

27 Garrido López, C.: Decisiones excepcionales y garantía jurisdiccional en la Constitución, Marcial Pons, Madrid, 2021, pp. 182 a 186. GARrido López, C.: «Sobre el estado de sitio, su régimen jurídico y el control jurisdiccional de su declaración», Revista de Derecho Político, n. ${ }^{\circ}$ 68, 2007, pp. 107 a 142. GARrido López, C.: «Naturaleza jurídica y control jurisdiccional de las decisiones constitucionales de excepción», Revista Española de Derecho Constitucional, n. ${ }^{\circ} 110,2017$, pp. 43 a 73. 
Constitución que actualizan una situación excepcional. Para estos autores, la fuerza de ley de los decretos es independiente a la intervención del Congreso de los Diputados; es consecuencia de su condición de normas necesarias para la efectividad de los estados del art. $116 \mathrm{CE}$. Y en cuanto que actos con fuerza de ley, su control compete exclusivamente el Tribunal Constitucional.

B) Un segundo sector doctrinal mantiene que el estatuto jurídico del decreto gubernamental de declaración del estado de alarma y la autorización parlamentaria de su prórroga son diferentes, de modo que también es diferente el órgano jurisdiccional para su control.

Inicialmente el prof. Mateu-Ros Cerezo ${ }^{28}$ y más tarde otros autores como el prof. Navas Castillo ${ }^{29}$ o el prof. Aragón Reyes ${ }^{30}$ distinguen el decreto de declaración de alarma del decreto de prórroga. Para estos autores, el primero no trasciende su consideración formal y tiene la naturaleza de disposición reglamentaria sometida al control de legalidad de la jurisdicción ordinaria. Por el contrario, el decreto de prórroga goza de valor y fuerza de ley ex art. 27.2.b LOTC porque su existencia depende de la autorización parlamentaria y, por consiguiente, está sujeto al control de constitucionalidad del Tribunal Constitucional.

En un trabajo del 2019, el prof. Ruiz Robledo ${ }^{31}$ incide en esta opción. Se refiere a las STC 83/2016 de 28 de abril y escribe: «...el fuero de un decreto de declaración del estado de alarma no depende de sí mismo, depende de si el Congreso autoriza su prórroga. En ese caso le correspondería al Tribunal Constitucional, pero si no fuera necesaria la prórroga (imaginemos unas lluvias torrenciales que obliguen a declarar el estado de alarma por diez días en una provincia cualquiera) entonces su control de legalidad sería competencia del Tribunal Supremo. Para evitar este poco lógico resultado (y por otros motivos en los que ahora no puedo detenerme, como es que el control consiste en una labor tan típica de la jurisdicción ordinaria como comprobar que si el decreto respeta la LOEAES) me atrevo a proponer que se modifique el artículo 12.1 de la Ley de la Jurisdicción Contencioso-Administrativa para que dentro de las funciones que le corresponden a la Sala de lo Contencioso-Administrativo del Tribunal Supremo en su primer apartado establezca: "Los actos y disposiciones del Consejo de Ministros y de las Comisiones Delegadas del Gobierno, incluidos los decretos de declaración del estado de alarma"».

28 Mateu-Ros Cerezo, R.: «Crisis del Estado y fuentes del Derecho», VV. AA.: Gobierno y Administración en la Constitución, Instituto de Estudios Fiscales, Madrid 1979, vol II, pp. 1399 a 1400.

29 Navas Castillo, C.: «Los estados excepcionales y su posible control por el Tribunal Constitucional», Revista de la Facultad de Derecho de la Universidad Complutense, n. ${ }^{\circ}$ 87, Madrid 1997, pp. 158 a 163.

30 Aragón Reyes, M.: «Acto con fuerza de ley» en Aragón Reyes, M. (coord.): Temas básicos de Derecho Constitucional, Civitas, Madrid 2001, vol. I, p. 342.

31 Ruiz Robledo, A.: «Problemas constitucionales del estado de alarma por la COVID-19 en España», Revista de Estudios Jurídicos, n. ${ }^{\circ} 38,2019$, pp. 83 a 104. También «El estado de alarma; donde quiere el gobernante». El País, edición del 6 de noviembre de 2020. 


\section{MI CAMBIO DE CRITERIO. JUSTIFICACIÓN}

Al principio de este trabajo di cuenta de que en sendos artículos de 1989 y $1990^{32}$ sostuve que tanto el decreto gubernamental de declaración del estado de alarma como la autorización parlamentaria para su prórroga tenían rango de norma reglamentaria, susceptible del control de legalidad por parte de la jurisdicción ordinaria. Mi actual reflexión conlleva cierto riesgo porque no solo discrepo de lo que sostuve treinta años atrás, sino que además disiento ahora de la doctrina del Tribunal Constitucional.

Ya no creo que tanto el decreto de declaración del estado de alarma como el de prórroga del estado de alarma tengan rango reglamentario. Las opiniones de los profs. Mateu-Ros Cerezo, Navas Castillo y Aragón Reyes me merecen crédito. El decreto de declaración del estado de alarma tiene la naturaleza de disposición reglamentaria sometida al control de legalidad de la jurisdicción ordinaria. Por el contrario, el decreto de prórroga goza de valor y fuerza de ley ex art. 27.2.b LOTC y, por consiguiente, está sujeto al control de constitucionalidad del Tribunal Constitucional.

En mi opinión, el argumento central es básico y fundamental: la doctrina de la división de poderes. No cabe que una norma adquiera rango de ley si no media alguna intervención del Poder Legislativo. En todas las normas con rango legal o interviene el Congreso y el Senado (la reforma constitucional, los estatutos de autonomía y las demás leyes orgánicas, leyes ordinarias, los tratados internacionales, los decretos legislativos) o solo el Congreso (el Reglamento del Congreso, los decretos leyes, los decretos de excepción y de sitio) o solo el Senado (el Reglamento del Senado, el acuerdo del art. 155 de la Constitución de la coerción esta$\left.\mathrm{tal}^{33}\right)$. La intervención del Parlamento es precisamente lo que dota de rango legal a una norma.

Es a lo que el prof. Alzaga Villaamil ${ }^{34}$ se refiere cuando habla de un tertium genus distinto de los decretos leyes y los decretos legislativos. Esta postura, un tanto ecléctica, fue criticada por el prof. Garrido López ${ }^{35}$ que la acusa de «paradójica»: «Pero, si el decreto de prórroga del estado de alarma tiene fuerza de ley, ¿puede en puridad el decreto de declaración del que trae causa carecer de ella habiendo previsto idénticas excepciones, suspensiones, modificaciones temporales del ordenamiento jurídico?, Una respuesta afirmativa carecería de sentido».

Según la doctrina del Tribunal Constitucional, el decreto del estado de alarma es la única norma del sistema de fuentes estatales que tiene rango legal sin

32 Lafuente Balle, J.M.a.: «Los estados... (I) y (II)», ops. cits.

33 Lafuente Balle, J.M. a: «El art. 155...», op. cit.; y «El art. 155 de...», op. cit.

34 Alzaga Villaamil, Ó.: Comentario sistemático a la Constitución española de 1978, Marcial Pons. Madrid 2016, p. 699.

35 Garrido López, C.: Decisiones excepcionales y garantía jurisdiccional de la Constitución, Marcial Pons, Madrid 2021, p. 184. 
ninguna intervención del Parlamento. No solo es un sinsentido constitucional, sino también democrático. El rango de ley es consecuencia de la intervención del Poder Legislativo, sin excepciones por graves que sean.

Por esta razón, a mi entender, al carecer de cualquier intervención parlamentaria, el decreto de declaración del estado de alarma tiene la naturaleza de disposición reglamentaria sometida al control de legalidad de la jurisdicción ordinaria y, eventualmente, es susceptible de recurso de amparo que, si se estimase, habría de dar lugar a una auto cuestión de inconstitucionalidad.

Por el contrario, a resultas de la intervención y autorización del Congreso de los Diputados, el decreto de prórroga goza de valor y fuerza de ley ex art. 27.2.b LOTC y, por consiguiente, está sujeto al control de constitucionalidad del Tribunal Constitucional.

No es una rara avis. El Parlamento adopta decisiones que no obstante carecer de la forma expresa de una ley, son disposiciones normativas con rango de ley porque media una habilitación constitucional. Estas disposiciones parlamentarias con fuerza de ley tienen rango legislativo y, por ende, su control es de constitucionalidad y compete al Tribunal Constitucional. La enumeración es exhaustiva: arts. 54, elección del Defensor del Pueblo; 57.3, sucesión en la Corona sin heredero; 57.4, exclusión de la sucesión en la Corona por matrimonio prohibido; 59.2, inhabilitación regia; 59.3, nombramiento de regente en ausencia del orden establecido; 60.1, nombramiento de tutor ab intestato o por orfandad; 63.3, declaración de guerra y paz; 72.2, elección de los miembros de las Mesas del Congreso y el Senado; 94.1, autorización de tratados internacionales; 99.3, nombramiento de Presidente del Gobierno; 99.5, disolución de cámaras por ausencia de investidura; 112, cuestión de confianza; 113, moción de censura; 116, declaración de los estados de alarma, excepción y sitio; 155, de la coerción estatal; 167.3 y 168.3, convocatoria de referéndum de reforma constitucional. El art. 161.2 CE se refiere a «disposiciones normativas con rango de ley» diferenciadas de las leyes propiamente dichas. Y la LOTC se hace eco en numerosos artículos: 27.2.b, 28.1, $29.2,31,32.1,33.1,33.2,39.1,40.1$.

\section{LAS TESIS DEL PROF. CARLOS GARRIDO LÓPEZ}

Especialista destacado en estas cuestiones y alineándose con autores como los profs. Aparicio Pérez ${ }^{36}$ o Porres Azkona ${ }^{37}$, el prof. Garrido López ${ }^{38}$ mantiene que

36 Aparicio Pérez, M. A.: «¿Hacia una nueva figura de actos políticos del Gobierno?» en VV. AA.: «El Gobierno en la Constitución y en los Estatutos de Autonomía», Diputación de Barcelona, 1985, p. 193.

37 Porres Azkona, J.: «La decisión sobre los poderes excepcionales», Revista Vasca de Administración Pública, n. ${ }^{\circ} 6,1983$, pp. 47 a 48.

38 Garrido López, C.: Decisiones excepcionales y garantía jurisdiccional en la Constitución, Marcial Pons, Madrid, 2021, pp. 182 a 186. GARRIDO LóPEZ, C.: «Sobre el estado de sitio, su régimen jurídico y el control 
los decretos de declaración y de prórroga del estado de alarma no son ni actos administrativos, ni actos de Gobierno, ni propiamente normas porque no establecen un mandato general que modifique el ordenamiento jurídico. Antes al contrario, son unos actos infraordenados a la Constitución que actualizan una situación excepcional. Son actos de aplicación inmediata de la Constitución que no tienen su apoyo en la Ley orgánica 4/1981, sino en el mismo art. 116 CE para la plena efectividad de los estados excepcionales. En su opinión, la fuerza de ley de los decretos es independiente a la intervención del Congreso de los Diputados. $\mathrm{Y}$ en cuanto que actos con fuerza de ley, su control compete exclusivamente el Tribunal Constitucional.

Abundando en esta idea, el prof. García Cuadrado ${ }^{39}$ parte de la distinción entre los conceptos de «fuerza de ley» como la cualidad que tiene una norma para derogar otras; «valor de ley» como la característica del monopolio de su enjuiciabilidad por el Tribunal Constitucional; y «rango de ley» como la superioridad jerárquica frente a las normas reglamentarias. Y concluye: «En cualquier caso, no puede dudarse que la expresión "actos con fuerza de ley" de la LOTC hace referencia a decisiones singulares (que no sean normas propiamente hablando) con eficacia similar o equivalente a la de una ley».

No son normas, no modifican el Ordenamiento jurídico más allá de la alteración provisional de los poderes públicos y el régimen jurídico de las libertades y los deberes; pero tienen una eficacia ad extra y erga omnes, similar o equivalente a la de una ley. Son actos constitucionales «primarios», cuya fuerza de ley resulta directamente de la propia Constitución porque inciden decisivamente en el devenir político del Estado, sin necesidad de ninguna intermediación normativa del Parlamento. Se convierten así en el tercer nivel normativo de la Constitución de emergencia, tras la Constitución, arts. 55.2, 116, y la Ley orgánica 4/1981. Regulan la defensa extraordinaria del Estado, conforman el sistema de fuentes del Derecho de excepción y constituyen título de habilitación y canon de legalidad de las disposiciones y actos administrativos. Tanto el decreto de declaración de la alarma como el decreto de prórroga son mandatos generales que se proyectan sobre un número indeterminado de casos singulares.

Para el prof. Garrido López el control de esos decretos compete exclusivamente al Tribunal Constitucional. El procedimiento será el del recurso de inconstitucionalidad ex art. 161.1.a CE o el de la cuestión de inconstitucionalidad ex art. $163 \mathrm{CE}$. Pero también conocerá de cuantos vicios materiales, procedimentales

jurisdiccional de su declaración», Revista de Derecho Político, n. ${ }^{\circ}$ 68, 2007, pp. 107 a 142. GARrido López, C.: «Naturaleza jurídica y control jurisdiccional de las decisiones excepcionales de excepción», Revista Española de Derecho Constitucional, n. ${ }^{\circ}$ 110, 2017, pp. 43 a 73. GARrido López, C.: «La naturaleza bifronte del estado de alarma y el dilema limitación-suspensión de derechos fundamentales», Teoría y Realidad Constitucional, n. ${ }^{\circ} 46$, 2021, pp. 371 a 408.

39 García Cuadrado, A.M.: "Aproximación a una teoría de los "actos constitucionales" ", Revista de Derecho Político, n. ${ }^{\circ}$ 46. UNED, Madrid 1999, pp. 63, 64, 83, 91. 
y competenciales incurran, a través de un recurso de amparo ex art. 42 LOTC o bien mediante un conflicto de competencias ex arts. 62 o 73 LOTC. El parámetro de la constitucionalidad vendrá conformado por la propia Constitución y la Ley orgánica 4/1981, además de cualquier otra norma delimitadora de las competencias de cada uno de los órganos afectados. Quien sea el recurrente habrá de poder alegar la vulneración de los presupuestos de hecho por conculcar los principios de proporcionalidad, adecuación y necesidad; o por afectar al ejercicio de derechos fundamentales bien por no estar mencionados en el art. 55.1 CE o bien porque aun estando mencionados, la declaración de la alarma no se constriñe a la «limitación» de derechos que le compete sino que se excede e incluye normas de auténtica suspensión de derechos.

De este modo, la Resolución del Tribunal Constitucional decidiría sobre la constitucionalidad o inconstitucionalidad de la norma conforme al art. 28.2 LOTC, pero no ya en virtud del principio de jerarquía, sino en virtud del principio de competencia de conformidad a la reserva material de ley orgánica que fija el art. 81.1 CE. Así pues, el control de constitucionalidad del Tribunal Constitucional afectaría a los elementos reglados del decreto (a) procedimentales, b) materiales, c) competenciales); pero en ningún caso a la oportunidad política de la declaración que solo compete al Gobierno y al Congreso.

Así pues, en consecuencia, queda excluida la jurisdicción ordinaria contencioso-administrativa porque son actos marcadamente constitucionales del Gobierno (art. 26.3 Ley del Gobierno) incardinados directamente en la Constitución. Para el prof. Garrido López, el control de constitucionalidad del decreto de declaración de la alarma no plantea conflicto porque es un acto simple que depende de la sola competencia del Gobierno. Sin embargo, el decreto de prórroga es un acto complejo integrado por dos actos simples (la solicitud gubernamental de la prórroga y la autorización parlamentaria) que, siendo imprescindibles para su perfección y contenido, no tienen eficacia ad extra ni erga omnes. Por esta razón, el control de la jurisdicción constitucional alcanza al decreto en cuanto que tiene eficacia ad extra y erga omnes; pero no a los dos actos anteriores que lo componen porque cada uno de ellos, por si mismos, carecen de eficacia jurídica externa ${ }^{40}$.

\section{RÉPLICA EN FAVOR DEL DIFERENTE RANGO JERÁRQUICO DE LOS REALES DECRETOS DE DECLARACIÓN DEL ESTADO DE ALARMA Y DEL DE PRÓRROGA DEL ESTADO DE ALARMA}

En mi opinión, la diferenciación entre fuerza, valor y rango de ley es meramente teórica y carece de trascendencia práctica para resolver la cuestión capital

40 Invoca algunos precedentes: STC 16/1984 de 14 de febrero; AATC 135/2004 de 20 de abril, $85 / 2006$ de 15 de marzo. 
que es determinar cuál es la jurisdicción competente para el control de los reales decretos de declaración del estado de alarma y de prórroga del estado de alarma.

El art. 25 de la Ley 50/1997 del Gobierno enumera las formas de las decisiones del Gobierno. El apartado c) establece que será la propia de un Real Decreto cuando aprueben normas reglamentarias. Y el apartado d) se refiere a los Acuerdos cuando no proceda la forma del Real Decreto. En las declaraciones de la alarma y sus prórrogas, el Gobierno ha optado por el Acuerdo. Ahora bien, los «Acuerdos» (como los Reales decretos) son normas de rango reglamentario.

La declaración del estado de alarma es un acto unilateral del Gobierno sin ninguna intervención del Parlamento. Por el contrario, la prórroga depende de la autorización del Congreso de los Diputados que habrá de determinar su ámbito territorial, duración y efectos. Es pues un acto complejo y desigual como, mutandis mutandi, el refrendo ministerial de los actos del Rey. La decisión corresponde al Congreso. La facultad del Gobierno es de mera iniciativa y su Acuerdo tiene como destinatario único al Congreso.

En cuanto que acto unilateral del Gobierno sin ninguna intervención de las Cortes Generales, el Real Decreto de declaración de un estado de alarma es una norma de rango reglamentario y, por ende, susceptible del control de la jurisdicción ordinaria contencioso-administrativa ex art. 106.1 CE.

Mi criterio se sustenta en el ATS 99/2020 de 4 de mayo. Ponente d. Jorge Rodríguez-Zapata Pérez: «Lo que se acaba de expresar no excluiría que en aquellas situaciones en las que, no se haya producido la dación de cuenta al Congreso o no haya recaído la autorización de prórroga parlamentaria que exige el artículo 116.2 CE (RCL 1978, 2836), la forma de decreto que revista la declaración de alarma pudiera recobrar su relieve a efectos de nuestro control jurisdiccional. Aunque el decreto de declaración de la alarma proceda del Gobierno como órgano constitucional, su control correspondería a esta Sala, como permite el artículo 2 a) de la LJCA (RCL 1998, 1741), respecto de lo que en nuestra jurisprudencia hemos denominado conceptos judicialmente asequibles» (por todas, sentencia de 20 de noviembre de 2013 (RJ 2013, 8339) (rec. 13/2013) o sobre los hechos determinantes. La declaración «argumentativa de la STC 83/2016 que se ha transcrito no lo impide en cuanto ha sido formulada por el Tribunal Constitucional al resolver un recurso amparo (AdeH 12 de la STC 83/2016) y no en sede de tribunal de control de constitucionalidad de las leyes.

Pero además la Jurisprudencia del Tribunal Europeo de Derechos Humanos viene manifestándose exigente en que la limitación de derechos se someta al principio de legalidad. Y la aprobación de la ley es una competencia del Parlamento: Buonomo Gärber y otros c. Italia (dec.) no. 63783/00 del 20 de mayo de 2003; Beyeler c. Italia [GC], no 33202/96, § 107, CEDH 2000-I); Ruspoli Morenés c. España, demanda 28979/07, de 28 de junio de 2011.

Por el contrario, en el procedimiento parlamentario de la prórroga del estado de alarma intervienen dos actos, uno del Gobierno y otro del Congreso de los Diputados, que han de coincidir para que la prórroga adquiera eficacia. Por si 
mismos, cada uno de esos dos actos carecen de toda eficacia. Solo en cuanto que acto complejo, compuesto por el acuerdo del Gobierno y la autorización del Congreso de los Diputados, integrará el ordenamiento jurídico como una norma susceptible de control. Y, a mi entender, precisamente a resultas de la intervención del Congreso de los Diputados, la prórroga devendrá un acto con fuerza de ley y su control competerá al Tribunal Constitucional.

Tampoco, en mi opinión, se entiende que el prof. Garrido López defienda de una parte que los decretos de alarma son actos constitucionales primarios con fuerza de ley que responden a la Constitución; y por otra parte que el parámetro de constitucionalidad de los procedimientos que conozcan la constitucionalidad del decreto de alarma sea la propia Constitución y ciertas normas legales interpuestas que resultan necesarias para determinar la conformidad o no del acto enjuiciado con la Constitución. A mi entender, el parámetro de constitucionalidad de los Reales decretos de declaración y prórroga del estado de alarma no se limita a la Constitución, sino que incluye la Ley orgánica 4/1981, además de la L.O.T.C. y el Reglamento del Congreso de los Diputados; pero entonces los decretos de alarma no pueden ser actos primarios sino normas infraconstitucionales como cualesquiera otras.

Esta estructura responde a la lógica del art. 116 de la Constitución y de la Ley orgánica 4/1981. El estado de alarma está concebido para solventar un problema de menos de 15 días y, por consiguiente, de menor trascendencia que los de los estados de excepción y los del estado de sitio. Los supuestos de hecho del art. 4 de la Ley orgánica enumeran este tipo de alteraciones de la normalidad: terremotos, inundaciones, incendios, paralización de servicios esenciales, desabastecimiento de productos de primera necesidad y... ¡epidemias! Ninguno de estos supuestos debería extenderse más allá de 15 días. Tampoco una crisis sanitaria. El caso de la COVID-19 era de todo punto imprevisible, ha trastocado la lógica del escalonado del art. $116 \mathrm{CE}^{41}$, y ojalá sea irreproducible. Pero como regla general, el plazo de 15 días habría de ser suficiente para resolver esos supuestos propios del estado de alarma. La prórroga debería ser muy excepcional. Por eso se prevé que el Gobierno por sí pueda decretar el estado de alarma; y que la autorización del Congreso de los Diputados sea necesaria en el improbable caso de que fuese preciso prorrogar el plazo del estado de alarma, es decir cuando se agrave la alteración de la normalidad. Y precisamente por eso, el control del decreto de declaración debería competer a la jurisdicción ordinaria. Solo cuando la alteración deviniese de mayor gravedad se impondrá la autorización del Congreso de los Diputados para prorrogar el estado de alarma (ya como un acto con fuerza y rango de ley) y el control del Tribunal Constitucional.

Por supuesto que la autorización parlamentaria de la prórroga de un estado de alarma no implica la convalidación de los ultra vires inconstitucionales en que

41 Torres del Moral, A.: Principios de Derecho Constitucional español. Universidad Complutense, Madrid, 2010, T. I, p. 581. 
hubiese incurrido el Real Decreto de declaración. Si el Real Decreto de declaración incluyó preceptos que excediesen el art. 116 CE y la Ley orgánica 4/1981, especialmente por lo que se refiere a los supuestos del art. 4 y las medidas del art. 11, el Real Decreto, será ilegal e inconstitucional. La posterior autorización de una prórroga por el Congreso no habría de implicar ninguna convalidación de lo que ya era ilegal e inconstitucional, no obstante lo escrito por el Magistrado Xiol Rius en su voto particular ( «Aunque se aceptara que el Consejo de ministros cuando aprobó el Real Decreto 463/2020 incurrió en una infracción de la Constitución al haber suspendido derechos fundamentales sin la previa autorización del Congreso, este vicio habría sido subsanado por esta Cámara al hacer suyas en su integridad las medidas acordadas por el Gobierno. El órgano competente para otorgar la autorización (el Congreso de los Diputados) al prorrogar las medidas adoptadas por el Consejo de Ministros, las confirmó, lo que supone asumir como propio lo acordado por el Gobierno.»).

Pero es que más allá de este debate académico, la defensa del Estado que es la ratio legis del art. $116 \mathrm{CE}$ no precisa para nada vulnerar el principio de división de poderes. En cuanto que ratio legis del art. $116 \mathrm{CE}$, la defensa extraordinaria del Estado no necesita de la compleja creación de ese tercer nivel normativo de la Constitución de emergencia, tras la Constitución, arts. 55.2, 116, y la Ley orgánica 4/1981, ni de ningún excepcional sistema de fuentes para constituir un título de babilitación y canon de legalidad de las disposiciones y actos administrativos. Es mucho más sencillo.

Se impone un mayor celo democrático en razón a que las dos declaraciones del estado de alarma han tenido por objeto la libertad de circulación. Es esta libertad un pilar para el ejercicio de otros derechos constitucionales: la tutela de los tribunales, el habeas corpus, la libertad de culto, la inviolabilidad domiciliaria, la libertad de información, el derecho de reunión y de manifestación, el derecho de asociación, el derecho a la educación, el derecho de sindicación...son todos derechos que presuponen la libertad de circulación. No es que la libertad de circulación sea un derecho especialmente protegido en la Constitución. Sus garantías son las comunes todos los derechos fundamentales y las libertades públicas. Pero sí que es una libertad que posibilita el ejercicio de todos esos otros derechos.

El Gobierno lo es en razón a que dispone de la confianza del Congreso de los Diputados y, por ende, de la mayoría de sus integrantes. Lo normal y previsible es que la alteración de la normalidad que ha de dar lugar a la declaración gubernamental del estado de alarma se solvente en un plazo no superior a 15 días. Ahora bien, si el Gobierno teme por la gravedad del terremoto, del desabastecimiento o de la crisis sanitaria, y pretende prorrogar y extender a más de 15 días la declaración del estado de alarma, no tiene más que pedir la inmediata autorización del Congreso. No precisa de ninguna mayoría cualificada; sino solo de la mayoría que le invistió ex art. 99 CE. Así de fácil. Declara el estado de alarma y de inmediato puede solicitar su prórroga por el tiempo que entienda necesario porque el art. 116.2 no establece un límite temporal para la prórroga. 
El Real Decreto de declaración de la alarma es declarado por el Gobierno sin ninguna intervención del Parlamento. Pero si el Gobierno quiere ampararse en la intervención del Parlamento, no tiene más que pedir al Congreso que autorice la prórroga y convierta el Real Decreto en un acto con fuerza de ley precisamente porque cuenta con la autorización del Poder Legislativo. Si de este modo, el Gobierno quiere evitar y zafar el control de la jurisdicción ordinaria, le bastaría con aprobar de forma sucesiva e inmediata el decreto de declaración del estado de alarma y el sometimiento de su prórroga a la autorización parlamentaria.

La lógica del art. 116.2 CE es aplastante. Si el estado de alarma responde a un problema menos grave y limitado en el tiempo, el Gobierno se basta de un decreto reglamentario impugnable ante la jurisdicción ordinaria. Pero si el supuesto de hecho es de mayor gravedad con expectativas de duración, puede solicitar la inmediata prórroga del Congreso de los Diputados a fin de que su decisión adquiera rango de fuerza de ley y su control pase al Tribunal Constitucional. Así de fácil. Sin forzar las costuras del texto constitucional; sin vulnerar para nada el principio de división de poderes.

$$
* * *
$$

TITLE: The Decreto de Alarma: Hierarchical status and constitutional review

ABSTRACT: In two articles I wrote in 1989 and 1990 I sustained that either the Decreto Gubernamental del Estado de Alarma (state of alarm pronouncement) or the Parliamentary authorization for its extension had the status of norma reglamentaria (regulatory standard), and the general jurisdiction was able to review their lawfulness. After twenty years, Section 116 of the Spanish Constitution and the Ley Organica 4/1981 regarding the COVID-19 pandemic have changed my mind. My concern is serious because I do not agree with the majority doctrine nor with the very Tribunal Constitucional. The Tribunal Constitucional judgements (Spanish Constitutional Court) (SSTC 83/2016, April 28th; 148/2021, July 14th) maintain that the Reales Decretos have force of law and, as a result, their review lie exclusively in the Tribunal in question. These Reales Decretos make up a "system of legal sources" that shifts general jurisdiction temporarily. The majority doctrine as well, whose main specialist if Professor Carlos Garrido López, joins this tendence and affirms that the Reales Decretos are primary constitutional actions, subordinated to the Constitution, and update an exceptional situation, therefore, its force of law is independent of that of the Congreso de los Diputados (Spanish Congress). Well then, I have changed my 1990 mind, and nowadays I think the nature of the decreto de declaracion del estado de alarma is that of a disposicion reglamentaria (regulation) whose control lies in the general jurisdiction. On the contrary, the decreto de prórroga (decree of extension) (as long as it needs the Congreso de los Diputados authorization) has force of law ex Section 27.2.b. LOTC (Ley Orgánica del Tribunal Constitucional) and, therefore, is subject to the Tribunal Constitucional review. The main reason for that is the separation of powers doctrine. A rule cannot rank with a statute without the intervention of the Legislative Power. Apart from that, the fact that this construction better answers the ratio legis of Section 116 of the Spanish Constitution; and the proportionallity between the event that altered the so-called normality and the steps and responsabilities that are in the office of the Government and the Parliament.

RESUMEN: En sendos artículos de 1989 y 1990 sostuve que tanto el decreto gubernamental de declaración del estado de alarma como la autorización parlamentaria para su prórroga tenían rango de norma reglamentaria, susceptible del control de legalidad por parte de la jurisdicción ordinaria. Más de veinte años después, la aplicación del art. 116 CE y la Ley orgánica 4/1981 en la pandemia del COVID-19 me han 
becho cambiar de opinión. Mi dificultad es tanto mayor cuanto que discrepo de la doctrina mayoritaria y del propio Tribunal Constitucional. El Tribunal Constitucional (SSTC 83/2016 de 28 de abril; 148/2021 de 14 de julio) sostiene que, en el estado de alarma, los Reales Decretos de declaración y de prórroga tienen rango $y$ fuerza de ley y, en consecuencia, su control compete en exclusiva al Tribunal Constitucional. Estos Reales Decretos integran un «sistema de fuentes del derecho de excepción» que desplaza temporalmente la legalidad ordinaria. También la mayor parte de la doctrina, de la que el profesor Carlos Garrido López es su principal especialista, se suma a esta corriente y argumenta que los Reales Decretos son unos actos constitucionales primarios, infraordenados a la Constitución, que actualizan una situación excepcional, de modo que la fuerza de ley de los decretos es independiente a la intervención del Congreso de los Diputados. Pues bien, he cambiado mi opinión de 1990. En la actualidad me mantengo en que el decreto de declaración del estado de alarma tiene la naturaleza de disposición reglamentaria sometida al control de legalidad de la jurisdicción ordinaria. Pero, por el contrario, sostengo que el decreto de prórroga (en cuanto que precisa de la autorización del Congreso de los Diputados) sí goza de valor y fuerza de ley ex art. 27.2. b LOTC y, por consiguiente, está sujeto al control de constitucionalidad del Tribunal Constitucional. El argumento central es la doctrina de la división de poderes. No cabe que una norma adquiera rango de ley si no media alguna intervención del Poder Legislativo. Amén de que esta interpretación responde mejor a la ratio legis del art. 116 CE y a la proporcionalidad entre el supuesto por el que la normalidad se haya alterado y las medidas y responsabilidades que han de corresponder al Gobierno y al Parlamento.

KEY WORDS: Decreto de Alarma, alarm state, Constitutional Court.

Palabras Clave: Decreto de Alarma, estado de alarma, Tribunal Constitucional.

FECHA DE RECEPCIÓN: 30.08.2021 FECHA DE ACEPTACión: 20.09.2021 